\title{
Acute alcohol toxicity and withdrawal in the emergency room and medical admissions unit
}

\author{
Author: Marsha Y Morgan ${ }^{\mathrm{A}}$
}

\begin{abstract}
Alcohol-related hospital attendances and admissions continue to escalate despite a fall in alcohol consumption levels in the UK population overall. People with alcohol-related problems pose a significant and often disproportionate burden on acute medical services as their management is often complex and challenging. This article focuses on the management of alcohol intoxication, with particular emphasis on aggressive and possibly violent behaviour; alcohol withdrawal; fitting; and the prevention and treatment of Wernicke's encephalopathy.
\end{abstract}

\section{Introduction}

People with alcohol problems are frequent attendees at accident and emergency departments and medical admission units. They manifest a wide range of problems, including alcohol intoxication, alcohol withdrawal and fitting, and aggressive and sometimes violent behaviour. In addition, they may have a whole host of other alcohol-related physical and psychosocial problems. Management of these individuals needs skill, knowledge and fortitude. However, opportunities should not be lost, whether patients are admitted or not, to assess their needs and refer appropriately to alcohol liaison services or other statutory/non-statutory bodies.

\section{Alcohol intoxication}

In naïve drinkers, blood alcohol concentrations of 150-250 $\mathrm{mg} / 100 \mathrm{ml}$ are usually associated with clinically apparent intoxication; concentrations of $350 \mathrm{mg} / 100 \mathrm{ml}$ are associated with stupor and coma; while concentrations of $>450 \mathrm{mg} / 100 \mathrm{ml}$ are often fatal. Individuals who habitually misuse alcohol often develop tolerance to its effects and are significantly less likely to develop intoxication than non-habitual drinkers.

Adults with mild to moderate intoxication can be managed satisfactorily in relatively simple surroundings with a minimum of medical support, but those who are severely intoxicated should be admitted and nursed in a high-dependency setting. Their level of consciousness should be assessed at least hourly;

Author: ${ }^{\text {A }}$ rincipal research associate and honorary consultant physician, UCL Institute for Liver and Digestive Health, Division of Medicine, Royal Free Campus, London, UK their cardiac activity should be continuously monitored; their urine output should be carefully recorded; and blood glucose, plasma electrolytes and blood gases should be measured every 4 hours until recovery is assured.

Intravenous fluids should be given to counter dehydration and to maintain urine output and plasma expanders may be required if circulatory collapse occurs; inotropic support may be necessary if severe hypotension persists. Hypoglycaemia should be corrected as quickly as possible with oral glucose, if the conscious level permits, or else with $5 \%$ or $10 \%$ IV dextrose, as required. Assisted ventilation may be needed if respiration is severely depressed. Haemodialysis may have a place in the management of individuals with exceptionally high blood alcohol concentrations, particularly if there are other metabolic complications, evidenced by an arterial $\mathrm{pH}$ of $<7$, or if other dialysable drugs have been ingested.

\section{Key points}

Alternative causes of impaired consciousness should be sought in adults with blood alcohol levels below $350 \mathrm{mg} / 100 \mathrm{ml}$.

Aggressive, intoxicated individual should be assessed, if possible, to identify factors such as injury or infection which might confound the clinical picture.

Individuals who are alcohol dependent should be admitted to hospital for assisted withdrawal if they have previously experienced severe withdrawal symptoms, have a history of fitting, significant comorbidities or complex social needs.

Fitting is associated with both alcohol intoxication and alcohol withdrawal and is best managed with benzodiazepines; prophylactic anti-epileptic medication should not be given.

Maintain a low threshold for provision of prophylactic thiamine supplementation to patients with alcohol problems, particularly those who are malnourished, have comorbid liver disease or are withdrawing from alcohol.

KEYWORDS: Alcohol intoxication, alcohol withdrawal, aggression, benzodiazepines, fitting, thiamine, Wernicke's encephalopathy 
Table 1. Features of acute alcohol withdrawal.

\begin{tabular}{|c|c|c|c|c|c|}
\hline Type & Onset $^{a}$ & Features & Offset & Fitting & Other features \\
\hline $\begin{array}{l}\text { Minor symptom } \\
\text { complex } \\
\text { (majority) }\end{array}$ & $6-8 h$ & $\begin{array}{l}\text { Generalised hyperactivity, anxiety, } \\
\text { tremor, sweating, nausea, } \\
\text { retching, tachycardia, systemic } \\
\text { hypertension, mild pyrexia } \\
\text { (Peak } 10-30 \text { h) }\end{array}$ & $40-50 \mathrm{~h}$ & Yes: first $12-48 \mathrm{~h}$ & $\begin{array}{l}\text { Auditory/visual hallucinations: } \\
\text { may last for 5-6 days }\end{array}$ \\
\hline $\begin{array}{l}\text { Delirium tremens } \\
(<5 \%)\end{array}$ & $48-72 \mathrm{~h}$ & $\begin{array}{l}\text { Coarse tremor, agitation, fever, } \\
\text { tachycardia, profound confusion, } \\
\text { delusions and hallucinations }\end{array}$ & $\begin{array}{l}\text { Fatal if not } \\
\text { effectively } \\
\text { treated }\end{array}$ & $\begin{array}{l}\text { No: may herald } \\
\text { the syndrome but } \\
\text { is not part of it }\end{array}$ & $\begin{array}{l}\text { Hyperpyrexia, ketoacidosis and } \\
\text { profound circulatory collapse if } \\
\text { not effectively curtailed }\end{array}$ \\
\hline
\end{tabular}

Several further complications can arise which will need additional skilled management; these include ketoacidosis, lactic acidosis, cardiac arrhythmias, hypokalaemia, inhalation pneumonia, venous thromboembolism and hyperpyrexia; hypoglycaemia may be delayed for up to 36 hours and is easily missed.

Alternative or additional causes for the change in conscious level should also be sought in adults who present in coma with blood alcohol concentrations of $<350 \mathrm{mg} / 100 \mathrm{ml}$. Cerebral trauma, cerebrovascular events and meningitis should be excluded, as far as possible. The presence of narcotic or other sedative drugs should be considered and information sought from the National Poisons Information Service (NPIS) in the UK and the National Poisons Information Centre in Ireland (NPIC). This service is accessed via www.toxbase.org and is freely available to UK NHS hospitals and general practices, NHS Departments of Public Health and HPA units. Severe or complex cases, including multiple ingestions and people with significant comorbidity, can be discussed with the relevant poisons service: UK NPIS 0844892 0111; Ireland NPIC (01) 8092566. Clinicians treating women who are pregnant can contact the UK Teratology Information Service 08448920909.

Metadoxine (pyridoxal L-2-pyrrolidine-5-carboxylate) has been shown to accelerate the elimination of alcohol in adults leading to faster recovery from intoxication and a more controlled withdrawal from alcohol. ${ }^{1-3}$ It is given as a single intravenous administration and has few, if any, side-effects. This product is not, however, licensed for use in the UK.

\section{The aggressive intoxicated drinker}

Although most intoxicated patients are cooperative, some may be belligerent, abusive and violent. The overriding priority in this situation is to ensure the patient's safety and that of attending staff, relatives/friends and bystanders. It is equally important to try to assess whether the patient is aggressive and disinhibited simply because they are intoxicated or because other factors, such as injury or infection, have added a component of confusion or delirium.

Every attempt should be made to create a calm environment. Those not immediately concerned with the patient's management should be asked to leave. Ensure that the room is clear of objects that can be thrown or used as weapons and that staff can exit easily and safely, if necessary. Try to defuse escalating anger by adopting a concerned and non-threatening demeanour. Remember there is little point in arguing with someone who is very drunk.

Many hospitals have security staff and police on standby; they should be summoned promptly if initial attempts to defuse the situation fail. Their intervention is rarely necessary but their presence is important to convey a clear message that violence will not be tolerated.

The patient should be offered 'something to calm them down'; sedatives should be used sparingly because of the danger of oversedation in an intoxicated patient and of masking other conditions affecting cerebral function. If the patient refuses help and their aggression continues to escalate it is probably best to try to isolate them in a safe environment rather than to forcibly restrain and sedate them. Restraint, if eventually necessary, should be undertaken by staff trained in the correct procedures. The drug of choice in this situation is haloperidol, administered parenterally. Subsequent, careful monitoring will be required, watching specifically for features of alcohol withdrawal.

If the patient is mentally ill, confused, disorientated, suicidal or significantly depressed then detention under the Mental Health Act may be needed; however, this is not justified in most situations of intoxication and aggressive behaviour.

\section{Alcohol withdrawal effects}

Approximately $40 \%$ of individuals who misuse alcohol will develop an acute withdrawal syndrome when they abruptly

\section{Box 1. High-risk patients who should be considered}

for admission to hospital for medically assisted withdrawal from alcohol.

$>$ History of seizures or delirium tremens during previous attendances/admissions.

> Significant or multiple comorbidities eg severe chronic depression, psychosis, unstable angina, heart failure, chronic liver or renal disease, malnutrition

$>$ Significant learning difficulties or cognitive impairment

$>$ Inadequate social support

$>$ Age $<18$ years

$>$ Older persons particularly if also frail

Pregnant women

Homeless persons 
Table 2. Sample fixed dose regimen for treatment of alcohol withdrawal with chlordiazepoxide.

\begin{tabular}{|c|c|}
\hline Time & Dosage \\
\hline Day 1 , ie first $24 \mathrm{~h}$ & $30 \mathrm{mg}$ qds \\
\hline Day 2 & $\begin{array}{l}20 \text { mg tds } \\
30 \text { mg nocté }\end{array}$ \\
\hline Day 3 & $\begin{array}{l}10 \text { mg tds } \\
20 \text { mg nocté }\end{array}$ \\
\hline Day 4 & $\begin{array}{l}5 \text { mg tds } \\
10 \text { mg nocté }\end{array}$ \\
\hline Day 5 & $\begin{array}{l}5 \text { mg mane } \\
10 \text { mg nocté }\end{array}$ \\
\hline Day 6 & 5 mg nocté \\
\hline THEN STOP & \\
\hline
\end{tabular}

A variable $5-10 \mathrm{mg}$ 'prn' dose can be prescribed for breakthrough symptoms occurring during the withdrawal period

stop or substantially reduce their alcohol intake. Most patients manifest a 'minor symptom complex or syndrome', while a relatively small proportion develop delirium tremens which, if untreated, can be fatal (Table 1).

Not all patients attending acute services with features of alcohol withdrawal need to be admitted. The decisions around this are complex and primarily driven by local practices and facilities. Some patients in early withdrawal, with no other risk factors, can be referred to alcohol liaison services and their withdrawal managed in the community. Clearly admission is mandatory for patients with symptoms of severe alcohol withdrawal, fitting and established delirium tremens. Admission is also recommended for patients thought to be at particular risk, including those who have a history of fitting, significant comorbidities or complex social needs (Box 1). ${ }^{4,5}$

Medically assisted withdrawal from alcohol in generally managed using a fixed-dose regimen of benzodiazepines. The benzodiazepines differ little in efficacy from one another but the longer acting drugs, diazepam and chlordiazepoxide, have a smoother more protracted effect.

However, accumulation may cause problems in patients with respiratory or hepatic impairment. The shorter acting drugs have little tendency to accumulate but their use is associated with a higher incidence of fitting. The drug of choice is given in high dosage on days $1-3$ and is then tapered over the next 4-7 days in response to the patient's condition. Patients' needs are extremely variable and so the dosage of medication is difficult to predict accurately. As a guide, the daily dosages commonly employed in the early phase of treatment might be diazepam $40 \mathrm{mg}$, chlordiazepoxide $120 \mathrm{mg}$ and lorazepam 8 $\mathrm{mg}$. After the third day, dose reduction of at least $25 \%$ daily is required (Table 2).

Consideration can be given, in settings where 24-hour assessment and monitoring are available, for adoption of a symptoms-triggered withdrawal regimen tailored to the individual patient's needs; patients are assessed at set time points and drug treatment provided if they need it, but withheld if they are comfortable/without symptoms.

Convulsions can be treated with intravenous diazepam in a dose of $0.15-0.25 \mathrm{mg} / \mathrm{kg}$ body weight (usually $10-20 \mathrm{mg}$ ) every
Box 2. Treatment of Wernicke-Korsakoff syndrome.

A presumptive diagnosis of Wernicke-Korsakoff syndrome should be made in patients with a history of alcohol misuse and one or more of the following otherwise unexplained symptoms:

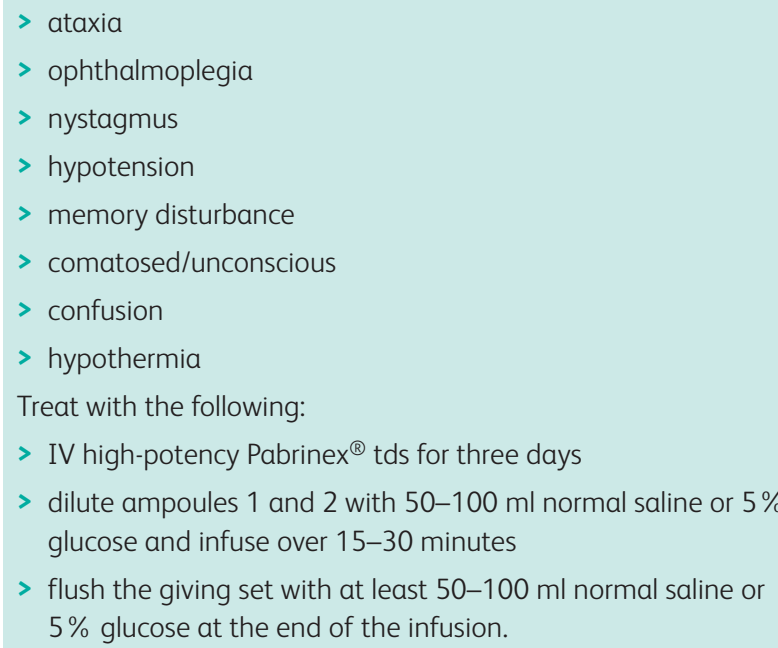

NO RESPONSE: discontinue and reassess.

RESPONSE: IV Pabrinex ${ }^{\circledR}$ od IV for five days or until no further improvement: then oral supplements for $2-4$ weeks.

4 hours by slow intravenous injection or infusion. Diazemuls (diazepam emulsion injection) is preferred to plain diazepam as it is less likely to cause thrombophlebitis. Lorazepam, given in a dose of $2-4 \mathrm{mg}(0.7 \mu \mathrm{g} / \mathrm{kg}$ : maximum $4 \mathrm{mg})$ by rapid bolus injection, is an alternative. Hallucinations may require treatment with lorazepam, haloperidol or olanzapine. Delirium tremens is best managed with lorazepam which may need to be given parenterally; haloperidol and olanzapine are alternatives.

Care must be taken to maintain the patient's general condition during the withdrawal period. Dehydration should be corrected by use of oral fluids; intravenous fluids should be avoided as overhydration is a serious potential hazard. Several biochemical abnormalities may be observed during the withdrawal period, for example, hypokalaemia and hypomagnesaemia, but these are usually transient and do not need specific correction; more persistent abnormalities will need to be corrected appropriately.

\section{Fitting}

Individuals who misuse alcohol may develop fitting when intoxicated. Fitting may also develop in alcohol-dependent individuals when they withdraw from alcohol. The fits should be brought under control with parenteral benzodiazepines but with great care as the blood alcohol concentration may still be significantly elevated. An electroencephalogram should be undertaken in all individuals experiencing this type of fitting for the first time, together with some form of cerebral imaging, either CT or MRI, in order to exclude potential underlying pathology. There is no indication for use of prophylactic antiepileptic medication in this setting.

Individuals who chronically misuse alcohol may suffer head trauma resulting in cerebral injury or subdural/ 
Table 3. Recommended regimens for prophylactic vitamin supplementation in alcohol misusers.

$\begin{array}{ll}\text { Situation } & \begin{array}{l}\text { Regimen } \\ \text { No need for additional }\end{array} \\ \text { > Well nourished } & \text { supplements but monitor } \\ \text { > Adequate dietary intake } & \\ \text { > No neuropsychiatric symptoms/signs } & \\ & \\ >\text { Mild malnutrition } & \text { Oral thiamine } \\ \text { > At risk of malnutrition } & \text { hydrochloride: } 100 \text { mg tds } \\ >\text { Compensated cirrhosis } & \text { for 2-4 weeks } \\ >\text { Acute alcohol withdrawal } & \\ & \\ >\text { Moderate/severe malnutrition } & \text { IV Pabrinex }{ }^{\circledR} \text { bd for } \\ \text { three days then oral } \\ >\text { Significant dietary neglect } & \text { supplementation for 2-4 } \\ >\text { Peoriphegligible dietary intake } & \text { weeks } \\ >\text { Decompensated cirrhosis } & \\ >\text { Severe acute withdrawal } & \end{array}$

extradural haematomas. These injuries may result in fitting, either at the time of the initial insult, or subsequently. These individuals are extremely difficult to manage. They may require long-term, antiepileptic medication but, if they continue to misuse alcohol, control may be difficult, if not impossible, to achieve.

\section{Wernicke's encephalopathy}

Individuals with alcohol problems are often thiamine deficient and are therefore at risk for developing Wernicke-Korsakoff syndrome. The classical triad of ophthalmoplegia, ataxia and confusion is rarely seen and a high threshold of suspicion should be maintained in patients with otherwise unexplained neurological findings (Box 2). Thiamine supplementation is required, and invariably provided in the $\mathrm{UK}$, as the mixed vitamin preparation Pabrinex ${ }^{\circledR}$. However, there is little or no evidence base on which to determine the dose, frequency, route or duration of thiamine treatment for prophylaxis against or treatment of Wernicke-Korsakoff syndrome in this setting. ${ }^{6}$ Several sets of guidance exist based primarily on pragmatic clinical consensus, ${ }^{4,7,8}$ resulting in a lack of consistency, confusion and poor uptake of best practice. 9,10

If there is any suspicion of Wernicke's encephalopathy treatment should be instituted promptly (Box 2). Prophylactic vitamin supplementation should also be prescribed in individuals identified as at risk with the dosage and route varied in relation to the perception of risk severity. It is not clear how long treatment should be continued to ensure adequate replenishment of thiamine stores - a safe margin should be allowed (Table 3 ).

Caution should be exercised when adopting the recommended practice of giving one dose of parenteral Pabrinex ${ }^{\circledR}$ to individuals attending acute services. ${ }^{7}$ Provision might mask the signs of impending Wernicke's with possible disastrous consequences making it vital that the patient is also given an adequate supply of oral thiamine supplementation to take away with them and clear advice about the need for compliance.

\section{Summary}

Patients with alcohol problems presenting to accident and emergency department and medical admissions unit are challenging and their management, as a consequence, is often suboptimal. These patients should be reviewed, and their management directed, by members of staff with relevant experience rather than by departmental juniors. Guidelines exist for the management of these patients, which can be modified to reflect local preferences and services, and should be used to facilitate application of best practice.

\section{References}

1 Díaz Martínez MC, Díaz Martínez A, Villamil Salcedo V, Cruz Fuentes C. Efficacy of metadoxine in the management of acute alcohol intoxication. J Int Med Res 2002;30:44-51.

2 Shpilenya LS, Muzychenko AP, Gasbarrini G, Addolorato G. Metadoxine in acute alcohol intoxication: a double-blind, randomized, placebo-controlled study. Alcohol Clin Exp Res 2002;26:340-6.

3 Addolorato G, Ancona C, Capristo E, Gasbarrini G. Metadoxine in the treatment of acute and chronic alcoholism: a review. Int $J$ Immunopathol Pharmacol 2003;16:207-14.

4 National Institute for Health and Care Excellence. Alcohol-use disorders: diagnosis, and clinical management of alcohol-related physical complications (CG100). London: NICE, 2010.

5 National Institute for Health and Care Excellence. Alcohol-use disorders: diagnosis, assessment and management of harmful drinking and alcohol dependence (CG115). London: NICE, 2011

6 Day E, Bentham PW, Callaghan R, Kuruvilla T, George S. Thiamine for prevention and treatment of Wernicke-Korsakoff Syndrome in people who abuse alcohol. Cochrane Database Syst Rev 2013;7:CD004033.

7 Thomson AD, Cook CC, Touquet R, Henry JA; Royal College of Physicians, London. The Royal College of Physicians report on alcohol: guidelines for managing Wernicke's encephalopathy in the accident and Emergency Department. Alcohol Alcohol 2002;37: 513-21.

8 Thomson AD, Marshall EJ. BNF recommendations for the treatment of Wernicke's encephalopathy: lost in translation. Alcohol Alcohol 2013;48:514-6.

9 Ward D, Murch N, Agarwal G, Bell D. A multi-centre survey of inpatient pharmacological management strategies for alcohol withdrawal. QJM 2009;102:773-80.

10 Thomson AD, Marshall EJ, Bell D. Time to act on the inadequate management of Wernicke's encephalopathy in the UK. Alcohol Alcohol 2013;48:4-8.

Address for correspondence: Dr MY Morgan, UCL Institute for Liver and Digestive Health, Division of Medicine, Royal Free Campus, Rowland Hill Street, London NW3 2PF, UK.

Email: marsha.morgan@ucl.ac.uk. 